\title{
0 (não) engaj amento em traduções da literatura afro-americana no Brasil: o caso de Filho Nativo, de Richard Wright
}

\author{
The (non) political engagement in \\ translations of the African-American \\ literature in Brazil: the case of Native Son \\ by Richard Wright
}

\begin{abstract}
Lauro Maia Amorim*
Resumo: 0 presente artigo discute o papel do (não) engajamento de tradutores na difusão da literatura afro-americana no Brasil, com foco nas traduções da obra Native Son (Filho Nativo), de Richard Wright, realizadas por Monteiro Lobato (1944), J usmar Gomes (1987) e Aurora Maria Soares Neiva (1995). Busca-se refletir em que medida a literatura afro-americana poderia ser interpretada, em uma tradução, como expressão literária de resistência e engaj amento, que poderia servir como um modelo de inspiração para a crítica social em relação à própria desigualdade "racial" no Brasil. Investiga-se em que medida as traduções analisadas podem se aproximar ou não de uma perspectiva politicamente engajada que se refletiria nas opções tradutórias.
\end{abstract}

Palavras-chave: Estudos da Tradução; literatura afro-americana; Native Son; Richard Wright; engaj amento.

*Professor do Departamento de Estudos Linguísticos e Literários da UNESP de São J osé do Rio Preto 
AMORIM, L. M. - O (não) engajamento em traduções da literatura afro-americana no Brasil: o caso de Filho Nativo, de Richard Wright

\begin{abstract}
This paper discusses the role of translators' (non) engagement in disseminating African-American literature in Brazil, with focus on translations of Native Son, by Richard Wright, undertaken by Monteiro Lobato (1944), J usmar Gomes (1987) and Aurora Maria Soares Neiva (1995). We analyze the extent to which AfricanAmerican literature could be interpreted as a model of inspiration for social criticism in regard to "racial" inequalities in Brazil. The paper investigates how the analyzed translations might get closer or not to a politically engaged perspective that could be reflected on the translators' options.
\end{abstract}

Keywords: Translation Studies; African-American literature; Native Son; Richard Wright; political engagement.

Desde pelo menos a década de 1980, com o chamado cultural turn nos Estudos da Tradução, tem-se manifestado um interesse renovado por um conhecimento sistemático dos fatores ideológicos e discursivos que se inscrevem nas traduções, o que pode ser atestado por obras antológicas como Manipulation of literature, editado por HERMANS (1985) e Translation/history/culture, por LEFEVERE (1992), além de trabalhos que têm situado a tradução no centro das relações entre poder e ideologia, como Apropos of Ideology e Translation and power, respectivamente organizados por Calzada PÉREZ (2003) e por TYMOCZKo e GeNTZLER (2002). Trabalhos como aqueles reunidos na edição especial Translation and minority, do periódico The Translator, organizado por Venuti (1998), focalizam a tradução e sua relação com minorias. Recentemente, Translation, resistance and activism, editado por TYMoczKo (2010), analisa os diferentes contextos em que se efetiva o compromisso dos tradutores com um posicionamento político e ideológico na realização de seus projetos tradutórios. É no quadro dessas considerações que se inscreve o presente trabalho, que buscará refletir sobre o papel do (não) engajamento do tradutor na tradução da literatura afro-americana no Brasil, com foco especial em três traduções da obra Native Son (Filho Nativo), 
AMORIM, L. M. - $O$ (não) engajamento em traduções da literatura afro-americana no Brasil: o caso de Filho Nativo, de Richard Wright

de Richard Wright, realizadas respectivamente por Monteiro Lobato (Companhia Editora Nacional, 1944), J usmar Gomes (Editora Best Seller, 1987) e Aurora Maria Soares Neiva (tese de doutoramento, 1995). ${ }^{1}$

As publicações acima mencionadas são de grande relevância para 0 conhecimento das relações entre tradução e intervenção, e do lugar discursivo ocupado pela tradução de obras literárias produzidas por minorias. Embora 0 interesse acadêmico pela tradução em face de questões políticas e ideológicas seja salutar, o tema da tradução da literatura afro-americana tem sido um tópico pouco abordado nos Estudos da Tradução, especialmente quando se considera o modo significativo pelo qual essa literatura se integra ao movimento mais amplo da diáspora negra internacional, na qual diferentes culturas afrodescendentes, fora da África, produziram sua própria história local, com linguagens imbuídas de novos significados, tal como é o caso das culturas de origem afro nos Estados Unidos, no Brasil e no Caribe, além de outras territorialidades.

0 que poderia explicar a existência de poucos trabalhos voltados para 0 estudo da literatura afro-americana e sua relação com a tradução seria, talvez, a percepção de uma ambivalência na constituição do lugar discursivo dessa literatura. Quando analisada em face da tradução, é possível que a literatura afroamericana não seja necessariamente vista como literatura minoritária, uma vez que pode ser visualizada tanto como uma experiência étnica singular em relação à história literária norte-americana quanto como naturalmente integrada a essa literatura, o que a aproximaria do centro das relações simbólicas a partir das quais a literatura norte-americana passa a ser vista efetivamente como uma literatura internacionalmente hegemônica. Assim, ao mesmo tempo em que se situa numa

\footnotetext{
${ }^{1}$ Este artigo é fruto de um projeto de pesquisa mais amplo que busca analisar, pela perspectiva dos Estudos da Tradução, o papel desempenhado por diferentes traduções e tradutores na divulgação da literatura afro-americana no Brasil, com foco especial no modo com que a(s) estética(s) afro-americana(s) têm sido historicamente reconstruídas pelo discurso tradutório em face das percepções identitárias e ideológicas provenientes das relações estabelecidas, no Brasil, entre cultura (afro-)brasileira, miscigenação e a (des)crença no mito da democracia racial.
} 
AMORIM, L. M. - O (não) engajamento em traduções da literatura afro-americana no Brasil: o caso de Filho Nativo, de Richard Wright

posição mais à margem em relação à centralidade com que se divulga o cânone literário norte-americano de cunho não étnico, a literatura afro-americana passa a se internacionalizar juntamente com a face hegemônica da literatura norteamericana em geral.

É possível que essa última condição seja o elemento discursivo que tenha proporcionado o interesse comercial efetivo pela publicação da tradução, assinada por Monteiro Lobato, do romance Native Son, de Richard Wright, em 1941, pela Companhia Editora Nacional. A obra obteve grande sucesso comercial nos EUA, 0 que impulsionou a aquisição dos direitos de sua publicação no Brasil. Embora Wright seja reconhecidamente um dos maiores nomes da literatura afroamericana, não somente pela qualidade de sua obra, mas também em face de seu posicionamento político em relação ao engaj amento do autor afrodescendente, a tradução de seu romance pela Companhia Editora Nacional não estabelece, em catál ogos ou nos paratextos de apresentação da obra, qualquer vínculo de natureza estética e/ ou política entre a obra em questão e seu lugar na literatura afroamericana em particular. A percepção que se criou na recepção da obra traduzida, à época, é de que a mesma era um grande sucesso representativo da literatura norte-americana, que passava a ocupar um lugar de referência internacional para a publicação de literatura estrangeira em tradução, que fora ocupado, antes da Segunda Guerra Mundial, pela literatura francesa.

A obra Native Son traz um prefácio assinado pelo próprio Wright, no qual o autor explica como concebeu o personagem principal do romance, Bigger Thomas, um jovem negro da periferia de Chicago, que passa a trabalhar como chofer de uma família branca muito rica. Bigger Thomas matou acidentalmente a filha do rico casal e, após se livrar do cadáver, busca dissimular sua atuação no crime, sendo posteriormente acusado de estupro e perseguido de modo implacável, após desvendarem parcialmente o caso (já que acreditam que ele a teria estuprado). No percurso de sua fuga, ele cometerá outros assassinatos, inclusive o de sua 
AMORIM, L. M. - $O$ (não) engajamento em traduções da literatura afro-americana no Brasil: o caso de Filho Nativo, de Richard Wright

namorada, Bessie. Bigger Thomas é uma figura marcada pela personalidade insubmissa, cujas falas, geralmente curtas, associam-se a pensamentos caracterizados por um sentimento tortuoso de revolta contra a sociedade racista na qual ele vive, juntamente com sua família, em condições de extrema precariedade. No prefácio, Wright desenvolve uma reflexão, em grande parte fundamentada na ideologia comunista, em torno do modo com que a sociedade capitalista norte-americana, por meio da segregação racial e da exclusão socioeconômica sistemática dos negros, teria tornado possível o surgimento de vários "Bigger Thomas" no país, cujas ações criminosas eram, de certa forma, resultado desse processo de exclusão. Wright desenvolve uma argumentação que busca alicerçar a construção de um personagem violento que é igualmente complexo: Bigger não quer se submeter às regras de convivência em um mundo que o convida a se retirar do espaço de qualquer dignidade humana. Pode-se dizer que o prefácio oferece ao leitor uma justificativa plausível para a existência conflituosa. É um gesto, no entanto, que busca se contrapor à interpretação que muitos fariam da obra àquela época: a de que o livro simplesmente confirmaria a violência e a brutalidade supostamente inerentes aos homens negros. Wright, com o prefácio, pretende oferecer um retrato das mazelas da sociedade norteamericana, apontando não para uma condição de violência que seria inerente aos negros, mas para a violência que a sociedade ajudava a fomentar e a reproduzir incessantemente. A situação dos negros nos Estados Unidos, incluindo a posição de Bigger Thomas, é associada, no prefácio, à condição de miséria e opressão que se vivia na Rússia pré-revolucionária, o que acentua o tom político, de natureza socialista, das considerações de Wright:

Eu me lembro de haver lido um trecho de um livro sobre a antiga Rússia que dizia: "devemos estar prontos para fazer sacrifícios infindáveis se quisermos estar preparados para derrubar o Czar." $E$, novamente, disse a mim mesmo: "Já ouvi isso alguma vez, em algum lugar antes". E mais 
AMORIM, L. M. - O (não) engajamento em traduções da literatura afro-americana no Brasil: o caso de Filho Nativo, de Richard Wright

uma vez eu ouviria Bigger Thomas, bem distante e há muito tempo, dizer a um branco que tentava se impor a ele: "vou te matar, vou pro inferno, e vou pagar por isso". Vivendo na América, eu podia ouvir palavras amargas da distante Rússia, sobre o cálculo trágico de quantas vidas humanas e de quanto sofrimento custaria a um homem viver como um homem em um mundo que lhe negava o direito de viver com dignidade. Ações e sentimentos de homens, a milhares de quilômetros de casa, me ajudaram a compreender os humores e impulsos daqueles que caminhavam nas ruas de Chicago e nas cidades do Sul (WRIGHT 1940/ 1966: xvii). ${ }^{2}$

Ressalta-se que o referido prefácio não foi incluído na tradução realizada por Monteiro Lobato. Em seu lugar, apresenta-se uma breve “introdução", oriunda de certos exemplares da obra original publicada em 1940, e assinada pela escritora norte-americana Dorothy Canfield Fisher. A abordagem de Fisher não é de todo diferente da de Wright, na medida em que há a mesma busca por demonstrar como uma sociedade desigual, como a norte-americana, é capaz de induzir à violência. O que é interessante, no entanto, é que o prefácio de Fisher busca estabelecer um paralelo entre a vida dos "moços negros" com as experiências de laboratório com as quais cientistas submetem os animais a todo tipo de pressão e estresse, levandoos a "neuroses e perturbações" (WRIGHT 1944: 09). Embora a autora reconheça que "essa mesma sociedade coloca os rapazes negros na situação do animal submetido a [essas] experiências" (WRIGHT 1944: 09), a dimensão propriamente política, que se faz presente no prefácio de Wright, e que irá relacionar mais diretamente essa situação de penúria e opressão ao sistema capitalista norte-americano, não é efetivamente tratado na introdução por Fisher. A associação entre comunismo e crítica à sociedade capitalista norte-americana não se faz presente na versão brasileira publicada pela Companhia Editora Nacional, o que não é uma mera

20 referido trecho foi traduzido pelo autor deste artigo, apesar de ser oriundo do prefácio de Wright, incluído na tradução de Jusmar Gomes, publicada pela editora Best Seller. As demais citações para as quais não há uma versão traduzida publicada também foram tradução nossa. 
AMORIM, L. M. - $O$ (não) engajamento em traduções da literatura afro-americana no Brasil: o caso de Filho Nativo, de Richard Wright

casualidade. A referida tradução teve sua primeira edição em 1941 (a utilizada para este artigo é de 1944), e era vinculada à coleção conhecida como "Biblioteca do Espírito Moderno", idealizada pelo então destacado educador Anísio Teixeira. Em carta datada de 1936 e endereçada a Monteiro Lobato, Anísio Teixeira revela seu desejo de criar uma coleção que, segundo FonSECA (2010: 10), “nutrisse o público leitor brasileiro e evitasse sua aproximação tanto do nazi-fascismo ('Itália e Alemanha') quanto do comunismo ('sanatório russo')". Anísio Teixeira declara na carta:

E então sonhei com aquele velho sonho de uma coleção de livros fundamentais. A toleima brasileira, que só 'reflete' telegramas e brochuras, está a pensar que só há, no mundo, os hospitais alemães e italianos e o sanatório russo para a cura da humanidade. Ora, é necessário mostrar-Ihes que há gente sã em 4/5 da terra e gente saníssima em uns países anglo-saxônicos e nórdicos. E essa gente é sã porque se nutre bem. E que a nutrição intelectual é tão precisa quanto a material. Quando não há nutrição intelectual é indispensável depois dietas especiais - e temos Itália, Alemanha e Rússia... Ora, a nutrição de hoje é o pensamento elaborado à vista do avanço das ciências e da democracia... A coleção seria, pois, de alimentos dessa espécie. Coleção de civilização contemporânea. Para dizer os corolários da ciência e da democracia (TEIXEIRA 1936 apud FONSECA 2010: 48).

Não é de se surpreender, portanto, que a não inclusão do prefácio de Wright seja coerente com a perspectiva ideológica da editora em relação à concepção da coleção por meio da qual a obra Native Son seria oferecida ao leitor: qualquer associação entre literatura e socialismo seria incompatível com a proposta de difusão da coleção, mormente associada aos valores (supostamente positivos) da democracia norte-americana. Sendo constituída de quatro séries (Filosofia, Ciências, História e Biografia, e Literatura), a coleção foi concebida para atender a demanda de um público crescente, o da classe média brasileira, cujos interesses 
AMORIM, L. M. - O (não) engajamento em traduções da literatura afro-americana no Brasil: o caso de Filho Nativo, de Richard Wright

de leitura, à época, se expandiam juntamente com o ensino primário e secundário no país. Em conexão com essa realidade, a coleção Biblioteca do Espírito Moderno, em catálogos e propagandas, era apresentada ao leitor com os seguintes obj etivos:

[...] A BIBLIOTECA DO ESPÍRITO MODERNO visa coordenar para o leitor brasileiro, dentre as obras consagradas pela aceitação pública, aquelas que mais diretamente buscam condensar, esclarecer e popularizar a herança cultural da espécie, tornando-a realmente e sem perda de nenhum dos finos e raros valores que sempre a caracterizaram quando não passava de legado atribuído a privilegiados eruditos, a herança comum e por todos partilhada. Além disso, incluirá à biblioteca documentos biográficos que nos familiarizem com os grandes homens e as grandes mulheres que souberam fazer de suas vidas um espetáculo de beleza ou de altura e, por esse modo, contribuíram para tornar a vida mais significativa e a civilização humana mais digna [...] (trecho de catálogos e orelhas de livros da Coleção Biblioteca do Espírito Moderno apud FONSECA 2010: 40).

A coleção Biblioteca do Espírito Moderno tinha, assim, o papel de popularizar materiais de natureza cultural, artística e científica que fossem condizentes com o "espírito" dos novos tempos. Ela tinha um compromisso com o aspecto "universal", ou em vias de "universalização", da cultura ocidental democrática, representada simbolicamente pela norte-americana, fartamente reproduzida nos livros da coleção. É compreensível, nesse contexto, que a noção de "literatura afro-americana", como locus de um saber estético específico, não se faça presente na divulgação do livro "Filho Nativo: tragédia de um negro americano". Vejamos uma das propagandas sobre a obra traduzida:

FILHO NATIVO é um romance extremamente emocionante... uma história que perturbará seu sono e assombrará sua imaginação. A leitura de FILHO NATIVO está vedada às pessoas de espírito morbidamente sensível, porque não há coração humano que não sinta abalar-se com o drama de Bigger Thomas, o personagem central deste grande romance de Richard Wright. FILHO NATIVO é a história trágica e brutal, mas profundamente 
AMORIM, L. M. - O (não) engajamento em traduções da literatura afro-americana no Brasil: o caso de Filho Nativo, de Richard Wright

humana de um preto que tenta encobrir seu complexo de inferioridade com atos agressivos contra a sociedade em que vive. FILHO NATIVO é uma obra prima da moderna literatura americana (Propaganda de Filho Nativo apud FONSECA 2010: 141).

A perspectiva que se constrói, na propaganda, é mais caracterizada pelo foco em torno da violência assustadora que demarca as ações de Bigger Thomas, como reação ao seu "complexo de inferioridade" perante a sociedade, e o cuidado de alertar o leitor "mais sensível" a isso, do que pelo estabelecimento de uma relação entre a exclusão socioeconômica sistemática a que ele e sua família são submetidos e seu caráter de insubmissão a qualquer forma de pressão social contra os negros. Torna-se claro que a percepção estética de Wright, ao conceber as ações violentas de Bigger Thomas como uma forma de crítica mais ampla às condições exasperantes de sobrevivência dos afro-americanos na sociedade capitalista norteamericana, não é o ponto fulcral da recepção tradutória da Coleção Biblioteca do Espírito Moderno. O reconhecimento dessa percepção crítica, caso tivesse ocorrido, teria tornado mais visível o papel de engajamento que a obra de Wright se propunha, tornando também mais visível o lugar discursivo da mesma no espaço crítico e estético da literatura afro-americana. A declaração final da propaganda busca afirmar a condição de obra prima de Filho Nativo, ao mesmo tempo em que a situa no campo da literatura americana moderna propriamente dita. Pode-se argumentar, é claro, que a noção de "literatura afro-americana" ainda não havia encontrado um espaço discursivo consolidado àquela época, sendo mais fácil situála, simplesmente, como produto da literatura norte-americana. Embora essa seja uma hipótese válida, a associação mais direta entre Filho Nativo e a modernidade literária norte-americana torna a obra mais atraente aos olhos do leitor, pela via do projeto modernizante da coleção Biblioteca do Espírito Moderno. Além disso, identificar a obra de Wright apenas como "literatura americana", sem qualquer outra relação com a dimensão discursiva de etnicidade a qual ela se filia, torna 
AMORIM, L. M. - O (não) engajamento em traduções da literatura afro-americana no Brasil: o caso de Filho Nativo, de Richard Wright

seu trabalho mais acessível e mais facilmente enquadrado na perspectiva identitária da nacionalidade, algo que é mais familiar ao modo como o próprio brasileiro tende a se identificar, já que, no Brasil, ela é um paradigma de identificação mais enraizado do que etnicidade, que se traduz pelo uso, mais recente, por exemplo, de hifenizações, como em "afro-americano" e "afrobrasileiro". Monteiro Lobato imprime certas marcas em sua tradução que refletem uma perspectiva ideológica particular, especialmente quando o tradutor faz referência à figura de Bigger Thomas e a membros de sua família. Os trechos selecionados abaixo representam diferentes passagens, do primeiro capítulo, que fazem referência à Bigger Thomas, a seu irmão e à sua mãe:

\section{Native Son - Richard Right (1940/1966) Filho Nativo, traduzido por Monteiro Lobato (Companhia Editora Nacional, 1944, negritos meus)}

"Aw, don't be so scary", Buddy said. (pp. 10)

- Não seja tão medrosa, respondeu o negro. (pp.16) [...]

Bigger laughed and approached the bed with the dangling rat [...] (pp. 11)

"You'll will regret how you living some day", she went on. (pp.13) [...]

o negro, a rir-se, aproximou-se da cama com o rato pendurado [...] (pp.16)

- Qualquer dia vai chorar de ter sido o que

é, continuou a preta. (pp.18) [...]

Bigger Thomas é referenciado, em inglês, pelo nome próprio ou pelo pronome sujeito "he" em outros momentos, sendo que o mesmo ocorre com a referência à sua mãe no último trecho (com o pronome "she"). No contexto dessas falas não há a presença de pessoas "não negras", representando, desse modo, momentos de discussão no âmbito doméstico, havendo apenas a presença de Bigger, de sua mãe e de seus dois outros irmãos, Vera e Buddy. Na tradução de Lobato, há uma referenciação sistemática a Bigger Thomas por meio do termo "o negro", que não parece ter o propósito de melhor identificar o personagem entre outros, já que Bigger não está entre brancos. Todavia, a depender do leitor, a 
AMORIM, L. M. - O (não) engajamento em traduções da literatura afro-americana no Brasil: o caso de Filho Nativo, de Richard Wright

impressão que isso causa, especialmente porque não ocorre no texto de partida, é a de um enquadramento que se distancia do que atualmente seria considerado como "politicamente correto". Referir-se a Bigger, em quase todo momento em que este fala ou faz algo, como "o negro", sugere uma forma de referenciação que pode soar, ao leitor contemporâneo, como um gesto "sutilmente" discriminatório. É particularmente perigoso porque, embora não devamos pressupor que o narrador onisciente seja o próprio autor, Wright, essa forma de referenciação não ocorre em nenhum momento na voz do narrador no texto em inglês, o que nos leva a questionar se isso seria, em parte, um reflexo inconsciente da inscrição do saber narratológico de um autor que se autoidentifica como negro. 0 que já não ocorre com Monteiro Lobato tradutor, cuja voz narrativa recriada na tradução fala por meio da perspectiva enunciativa de alguém que não é negro. Pode-se aventar que o efeito criado, na tradução, é de intensificação do gesto de referenciação que se afasta da neutralidade que seria demarcada apenas por "ele disse" ou "respondeu ele", enquadrando, assim, o personagem de Bigger Thomas num sistema referencial opositivo no qual "o negro" se contrasta, e se opõe, ao lugar enunciativo daquele que o descreve, o do "não negro".

Há outros aspectos reveladores do modo como o tradutor e escritor, Monteiro Lobato, em conformidade com a proposta da coleção, empreende sua leitura tradutória, comparada à tradução de J usmar Gomes. Os trechos a seguir tratam do diálogo entre Bigger Thomas e sua namorada, Bessie, que sugere a ele que as pessoas irão acusá-lo de estupro, mesmo não tendo sido esse o real motivo da morte de Mary, a jovem garota branca morta por ele. Tendo chegado bêbada em sua mansão, de madrugada, Mary foi levada para seu quarto por Bigger Thomas, que, como chofer, a trouxera de carro. Tendo-a colocado sobre a cama, Bigger se assustou quando foi "surpreendido" pela mãe da garota, a qual, no entanto, sendo cega, não percebeu sua presença no quarto. Para dissimular sua presença, Bigger sufoca Mary com o travesseiro, supondo que ela poderia falar alguma coisa, ainda 
AMORIM, L. M. - O (não) engajamento em traduções da literatura afro-americana no Brasil: o caso de Filho Nativo, de Richard Wright

que inconscientemente devido à bebida, que remetesse à sua presença no recinto. Bigger supunha que um negro não poderia estar no mesmo quarto de uma garota branca sem ser acusado de toda forma de abuso e leviandade. Focalizam-se, no trecho traduzido, as diferentes traduções das passagens em que aparece "rape" no texto original:

\author{
Native Son - Richard Wright \\ (1940/1966, \\ negritos meus) \\ pp. 213-14,
}

Filho Nativo, traduzido por Monteiro Lobato (Companhia Editora Nacional, 1944, pp. 21415 , negritos meus)

"They'Il.....They'll say you raped her."

Bigger stared. He had entirely forgotten the moment when he had carried Mary up the stairs. So deeply had he pushed it all back down into him that it was not until now that its real meaning came back. They would say he had raped her and there would be no way to prove that he had not. That fact had not assumed importance in his eyes until now. He stood up, his jaws hardening. Had he raped her? Yes, he had raped her. Every time he felt as he had felt that night, he raped. But rape was not what one did to women. Rape was what one felt when one's back was against a wall and one had to strike out, whether one wanted to or not, to jeep the pack from killing one. He committed rape every time he looked into a white
- Eles vão dizer que você Ihe fez mal.

Bigger arregalou os olhos. Havia se esquecido completamente do momento em que conduzira Mary para 0 quarto. Só agora Ihe vinha a possível interpretação daquilo. Eles iam dizer que ele a violentara - e como provar que não? Só agora aquele fato assumia importância aos seus olhos. Bigger levantou-se, cerrando as maxilas. Haviaa realmente violentado? Sim, ele a tinha violentado. Sempre que se sentia como naquela noite, violentava. Violência não é estupro. Violência é o que uma pessoa sente quando está encostada à parede e tem de lutar, queira ou não, para a defesa da própria vida. Ele cometia violência sempre que olhava para a cara dum branco. Ele era
Filho Nativo, traduzido por J usmar Gomes (Best Seller, 1987, pp.252, negritos meus)

- Eles... eles vão dizer que você violentou ela.

Bigger ficou pensativo. Havia esquecido, inteiramente, o momento em que levou Mary para seu quarto. Aquele episódio havia ficado tão oculto em sua memória que apenas agora é que seu verdadeiro significado estava de volta. Eles diriam que Bigger violentara a moça e não havia maneira de provar sua inocência. Esse fato não tivera importância até agora. Ficou em pé, os lábios apertados. Ele a violentara? Sim, ela a tinha violentado. Sempre que sentia o que sentira naquela noite, fazia alguma coisa errada. Mas as coisas erradas não eram aquelas cometidas contra as mulheres. Um sentimento de ter cometido algum erro era o que experimentava quando tinha as costas contra uma 
AMORIM, L. M. - O (não) engajamento em traduções da literatura afro-americana no Brasil: o caso de Filho Nativo, de Richard Wright

face. He was a long, taut piece of rubber which a thousand white hands had stretched to the snapping point, and when he snapped it was rape. But it was rape when he cried out in hate deep in his heart as he felt the strain of living day by day. That, too, was rape. um pedaço de borracha que mil mãos brancas esticavam até 0 último ponto - e se a borracha voltava, era violência. Era violência quando ele gritava de ódio, sentindo em seu coração o peso esmagador da vida diária. Violência, sim... parede e tinha de lutar, quisesse ou não, como para evitar que uma multidão o linchasse. Sentia que fazia algo errado todas as vezes que olhava para um rosto branco. Ele era como uma longa peça elástica que mil mãos brancas haviam esticado até o ponto de ruptura, e quando ele se rompia fazia coisas erradas. Mas será que ninguém via que era errado quando ele gritava com um medo que lhe vinha do fundo do coração, quando sentia a tensão de viver 0 dia-adia. Aquilo, também, era errado.

Embora o verbo "to rape" possa ser traduzido por "violentar", esta não deixa de ser uma opção menos impactante do que "estuprar", palavra que evoca, de modo mais explícito, até mesmo pela sua sonoridade, 0 ato de atacar sexualmente uma pessoa. No texto de partida, o narrador adentra os pensamentos de Bigger Thomas, que passa a considerar o "estupro" algo mais amplo, ao qual sua vida era diariamente submetida. Ao traduzir o substantivo "rape" por "violência", Lobato imprime uma generalidade ao termo, em português, deixando de associar a violência da vida diária de Bigger Thomas ao próprio gesto de um "estupro" social. A passagem mais polêmica seria talvez a que afirma que "but rape was not what one did to women" ("mas estupro não era o que se fazia a uma mulher"). A passagem foi, de certa forma, omitida, tendo sido traduzida por "violência não é estupro". Na realidade, seria justamente o contrário: a violência a que ele e sua família eram submetidos representava, para Bigger Thomas, uma forma de estupro que ele mesmo reproduzia, o que é confirmado no final da narração, quando se afirma que "that, too, was rape" ("isso, também, era 
AMORIM, L. M. - O (não) engajamento em traduções da literatura afro-americana no Brasil: o caso de Filho Nativo, de Richard Wright

estupro"), traduzido, de forma mais genérica, por "violência, violência sim...". Essa opção mais genérica por "violência", em vez de "estupro", pode ser uma tentativa de se amenizar o discurso crítico mordaz de Wright no sentido de evitar uma linguagem possivelmente menos compatível com a proposta de "ilustração", "esclarecimento" e "saber" subjacentes à iniciativa da coleção em que se insere a tradução.

Nota-se também que a tradução de Native Son, por Jusmar Gomes, publicada pela editora Best Seller, em 1987, segue uma linha de interpretação semelhante à da tradução de Lobato, pelo menos no diz respeito ao mesmo trecho, no qual "rape" é traduzido por opções menos impactantes, como "erro(s)", "algo errado" e "coisas erradas". Torna-se evidente, na tradução de J usmar Gomes, que a passagem relativa ao estupro parece ser "forte" demais para ser associada à violência da vida diária de Bigger Thomas. É como se a comparação entre miséria e estupro social fosse, no mínimo, algo demasiadamente "forçado", que escaparia à possibilidade de se fomentar qualquer empatia entre o leitor brasileiro e a figura controversa do protagonista. Além disso, a imagem do estupro tende a estar mais amplamente associada à violência contra a mulher, e não contra um homem que se torna cada vez mais violento em virtude da sua relação conflituosa com a sociedade que o cerca. A tradução de J usmar Gomes, diferentemente da versão de Lobato, apresenta o prefácio "Como nasceu Bigger", assinado por Wright ${ }^{3}$. Pode-se afirmar que a própria apresentação da obra, na orelha do livro, é reveladora de uma interpretação que fortalece uma imagem mais humana de Bigger Thomas, cujas ações, ainda que aterradoras, são justificadas pelo seu próprio drama:

\footnotetext{
3 Deve-se considerar que a apresentação do prefácio de Wright na tradução da Best Seller, em 1987, embora louvável, é menos impactante do que ela teria sido durante os anos 40, caso tivesse sido incluída na tradução de Lobato, já que, ao final dos anos 80 , o socialismo já não representava mais um perigo iminente para o mundo capitalista.
} 
AMORIM, L. M. - $O$ (não) engajamento em traduções da literatura afro-americana no Brasil: o caso de Filho Nativo, de Richard Wright

\begin{abstract}
Desde o início, Bigger Thomas está predestinado a um triste fim. Ele é um negro do South Side de Chicago, vive cercado de ratos e de rebeldes sem causa; um negro num mundo de brancos. Acabaria na prisão por algum furto, mas acidentalmente chega a ela por assassinato. Da primeira vez, em pânico, Bigger mata sem premeditação, envolvido por força que não pode entender ou controlar. Depois, na violência, ele descobre um sentido de liberdade e humanidade, embora de forma distorcida. Um sentido que a namorada, com seu alcoolismo, e a própria mãe, com a religião, não puderam mostrar-lhe. Romance clássico, repleto de emoção e sofrimento, Filho Nativo retrata um marginal que encobre seus complexos com agressões contra a sociedade em que vive, responsável direta por seu drama. Ilustra os efeitos corrosivos de um ambiente adverso, e sua força nos dá a conhecer e sentir a verdade do que o homem faz ao homem. É esta obra-prima, em nova tradução, que a Best Seller oferece agora à admiração da atual geração de leitores (WRIGHT 1987: 1a. Orelha, negrito no original).
\end{abstract}

A tradução de J usmar Gomes de certa forma se contrapõe a certos aspectos da tradução de Lobato. Em primeiro lugar, é uma versão nova lançada em 1987, após várias décadas desde a primeira edição da tradução de Lobato, a qual posteriormente ficaria esgotada no mercado livreiro. Nesse sentido, a tradução de Gomes expressa um linguajar mais atualizado. Em segundo lugar, a tradução de Gomes evita, por exemplo, o uso da referenciação à figura de Bigger Thomas por meio do uso frequente de "o negro", como o faz Lobato, produzindo, assim, uma impressão de neutralidade, por parte do narrador, no processo de referenciação. Há diferenças importantes também no que diz respeito ao tratamento da representação socioletal na tradução tanto de Lobato quanto na de J usmar Gomes, o que também pode ser observado na versão de Aurora Neiva, comentada mais adiante. A narrativa de Wright é caracterizada por diferenças socioletais relevantes entre os personagens. Bigger Thomas, sua família e seus amigos negros mais próximos, por exemplo, falam um inglês não padrão, que caracteriza 0 chamado inglês vernacular afro-americano (IVAA, conhecido como Black English), também presente na fala de outros três personagens negros: Jim, Jack e 0 
AMORIM, L. M. - O (não) engajamento em traduções da literatura afro-americana no Brasil: o caso de Filho Nativo, de Richard Wright

reverendo Hammond, pastor da igreja frequentada pela mãe de Bigger Thomas. Além da presença do IVAA, faz-se presente também o inglês padrão característico da fala dos personagens brancos (aliado a algum coloquialismo), e na voz do narrador em terceira pessoa. Na próxima passagem, pode-se fazer um contraste bastante revelador dos estilos das três traduções, especialmente no que diz respeito à tradução da variante IVAA presente nas falas de dois personagens negros: J im e Jack. No contexto do diálogo (aqui resumido), esses dois moradores negros da periferia começam a discutir sobre a inocência ou não de Bigger Thomas, que, em sua fuga frenética da polícia de Chicago, se depara com a moradia em que se encontram os dois homens, e passa a ouvir a sua discussão, sem que percebam sua presença do lado de fora:

\begin{tabular}{|c|c|c|c|c|}
\hline $\begin{array}{l}\text { Native Son }- \\
\text { Richard Right } \\
\text { (1940/1966, } \\
\text { pp.235-36) }\end{array}$ & $\begin{array}{l}\text { Filho } \\
\text { traduzido } \\
\text { Monteiro } \\
\text { (Companhia } \\
\text { Nacional, 19 } \\
\text { 233-35) }\end{array}$ & $\begin{array}{r}\text { Nativo, } \\
\text { por } \\
\text { Lobato } \\
\text { a Editora } \\
944, \text { pp. }\end{array}$ & $\begin{array}{lr}\text { Filho } & \text { Nativo, } \\
\text { traduzido } & \text { por } \\
\text { Jusmar } & \text { Gomes } \\
\text { (Best Seller, 1987, } \\
\text { pp. 273) }\end{array}$ & $\begin{array}{lr}\text { Filho } & \text { Nativo, } \\
\text { traduzido } & \text { por } \\
\text { Aurora } & \text { Soares } \\
\text { Neiva, (1995, pp. } \\
\text { 518) }\end{array}$ \\
\hline $\begin{array}{l}\text { "Jack, yuh mean } t^{\prime} \\
\text { stan' there 'n' say } \\
\text { yuh'd give tha' } \\
\text { nigger up t' the } \\
\text { white folks?" }\end{array}$ & $\begin{array}{l}\text { - Jack, se } \\
\text { conhecesse } \\
\text { entregava-o } \\
\text { brancos? }\end{array}$ & $\begin{array}{l}\text { você } \\
\text { o negro } \\
\text { aos }\end{array}$ & $\begin{array}{l}\text { - Jack, quer dizer } \\
\text { que você teria } \\
\text { coragem de } \\
\text { entregar aquele } \\
\text { negros pros } \\
\text { brancos? }\end{array}$ & $\begin{array}{l}\text { - Jack, tu tá } \\
\text { dizeno que tinha } \\
\text { corage de dedurá } \\
\text { aquele criolo pros } \\
\text { branco? }\end{array}$ \\
\hline $\begin{array}{l}\text { "Damn right Ah } \\
\text { would!" }\end{array}$ & $\begin{array}{l}\text { —Por Deus, } \\
\text { sim! }\end{array}$ & & - Podes crer! & - Craro que tinha. \\
\hline $\begin{array}{l}\text { "But, J ack, s' pose } \\
\text { he ain' guilty?" }\end{array}$ & $\begin{array}{l}\text { - Mas, J ack, } \\
\text { ele não fosse } \\
\text { culpado? }\end{array}$ & & $\begin{array}{l}\text { - Mas, J Jack, e se o } \\
\text { cara não for } \\
\text { culpado? }\end{array}$ & $\begin{array}{l}\text { - Mas, Jack, e } \\
\text { s' ele num é } \\
\text { culpado? }\end{array}$ \\
\hline $\begin{array}{l}\text { "Whut in hell he } \\
\text { run off fer then?" }\end{array}$ & $\begin{array}{l}\text { - Se não fos } \\
\text { como estaria } \\
\text { persegui-lo? }\end{array}$ & $\begin{array}{l}\text { sse, } \\
\text { am a }\end{array}$ & $\begin{array}{l}\text { - Então porque é } \\
\text { que ele se mandou? }\end{array}$ & $\begin{array}{l}\text { — Então porque foi } \\
\text { qu' ele fugiu? }\end{array}$ \\
\hline $\begin{array}{l}\text { "Mabbe he thought } \\
\text { they wuz gonna }\end{array}$ & $\begin{array}{l}\text { - Quem sab } \\
\text { querem bota }\end{array}$ & $\begin{array}{l}\text { e se } \\
\text { ar a }\end{array}$ & $\begin{array}{l}\text { - Vai ver que ele } \\
\text { pensou que os }\end{array}$ & $\begin{array}{l}\text { - Talvez ele fugiu } \\
\text { porque acho }\end{array}$ \\
\hline
\end{tabular}


AMORIM, L. M. - O (não) engajamento em traduções da literatura afro-americana no Brasil: o caso de Filho Nativo, de Richard Wright

\begin{tabular}{|c|c|c|c|}
\hline $\begin{array}{l}\text { blame the murder } \\
\text { on him!" }\end{array}$ & $\begin{array}{l}\text { culpa do crime nas } \\
\text { costas dele? }\end{array}$ & $\begin{array}{l}\text { brancos iam jogar a } \\
\text { culpa nas costas } \\
\text { dele. }\end{array}$ & $\begin{array}{l}\text { qu'iam botá a } \\
\text { culpa nele! }\end{array}$ \\
\hline $\begin{array}{l}\text { "Lissen, Jim. Ef he } \\
\text { wuzn't guilty, then } \\
\text { he oughta stayed } \\
\text { 'n' face it. Ef Ah } \\
\text { knowed where tha' } \\
\text { nigger wuz Ah'd } \\
\text { turn im up 'n' git } \\
\text { these white folks } \\
\text { off me." }\end{array}$ & $\begin{array}{l}\text { - Escute, Jim. Se } \\
\text { ele não fosse } \\
\text { culpado, então } \\
\text { devia apresentar-se } \\
\text { e enfrentar os } \\
\text { brancos. Se eu } \\
\text { soubesse onde anda } \\
\text { esse negro, juro } \\
\text { que o denunciaria, } \\
\text { para sossegar o }\end{array}$ & $\begin{array}{l}\text { - Escuta, Jim. Se o } \\
\text { cara não fosse } \\
\text { culpado, então } \\
\text { tinha mais é que } \\
\text { ficar lá e enfrentar } \\
\text { a barra. Se eu } \\
\text { soubesse onde é } \\
\text { que tá aquele } \\
\text { negro, eu } \\
\text { entreqava ele pros }\end{array}$ & $\begin{array}{l}\text { - Escut'aqui, Jim. } \\
\text { S'el' é inocente, } \\
\text { então devia ficá e } \\
\text { enfrentá a barra. } \\
\text { S'eu soubesse onde } \\
\text { é aquele criolo } \\
\text { tava, entregava ele } \\
\text { e tirava esses } \\
\text { branco do meu pé. }\end{array}$ \\
\hline$[\ldots]$ & $\begin{array}{l}\text { bairro. } \\
{[\ldots]}\end{array}$ & $\begin{array}{l}\text { brancos e livrava } \\
\text { minha pele. } \\
{[\ldots]}\end{array}$ & {$[\ldots]$} \\
\hline $\begin{array}{l}\text { “But, J ack, who's } \\
\text { stirring up trouble } \\
\text { now? The papers } \\
\text { say they beating' } \\
\text { us up all over the } \\
\text { city. They don' } \\
\text { care whut black } \\
\text { man they git. We's } \\
\text { all dogs in they } \\
\text { sight! Yuh gotta } \\
\text { stan' up 'n' fight } \\
\text { these folks." }\end{array}$ & $\begin{array}{l}\text { - Mas, Jack, quem } \\
\text { está provocando os } \\
\text { brancos? É o } \\
\text { contrário. Os } \\
\text { jornais estão cheios } \\
\text { de provocações dos } \\
\text { brancos - } \\
\text { espancamentos, } \\
\text { coisas. Nós somos } \\
\text { todos uns cães, } \\
\text { para eles. Temos de } \\
\text { resistir. }\end{array}$ & $\begin{array}{l}\text { - Mas, J ack, que é } \\
\text { que tá criando } \\
\text { encrencas agora? Os } \\
\text { jornais estão } \\
\text { dizendo que eles } \\
\text { estão espancando } \\
\text { negros em todos os } \\
\text { pontos da cidade. } \\
\text { Eles não tão dando } \\
\text { a mínima pra } \\
\text { procurar saber se o } \\
\text { negro é culpado ou } \\
\text { inocente. Pra eles } \\
\text { todos os negros são } \\
\text { piores que } \\
\text { cachorro! A gente } \\
\text { precisa se unir e } \\
\text { lutar contra essa } \\
\text { situacão. }\end{array}$ & $\begin{array}{l}\text { - Mas, Jack, quem } \\
\text { é que tá criano } \\
\text { pobrema agora, } \\
\text { hein? Saiu um } \\
\text { monte de notiça no } \\
\text { jornal falano que } \\
\text { andaro dano } \\
\text { porrada nos negro } \\
\text { aí pela cidade. Num } \\
\text { tão quereno nem } \\
\text { sabe que é a } \\
\text { pessoa; só precisa } \\
\text { sê negro. A gente é } \\
\text { tudo a merma coisa } \\
\text { pra eles: cachorro! } \\
\text { Nós temo que se } \\
\text { uní e lutá contra } \\
\text { esse pessoal. }\end{array}$ \\
\hline
\end{tabular}

Pode-se notar que, no texto de Wright, representa-se a condição socioeconômica dos dois personagens negros em suas falas, marcadas pelo inglês não padrão. Como já era de se prever, o texto de Lobato mantém a variedade padrão da língua portuguesa, o que pode ser observado, por exemplo, com o emprego sistemático de pronomes oblíquos em posição de ênclise, como na 
AMORIM, L. M. - O (não) engajamento em traduções da literatura afro-americana no Brasil: o caso de Filho Nativo, de Richard Wright

primeira fala: "Jack, se você conhecesse o negro entregava-o aos brancos?", o que deixa a fala do personagem mais artificial, por duas razões: a língua portuguesa em sua modalidade falada no Brasil tende a fazer uso de pronomes em posição proclítica, ou seja, anterior ao verbo, e de pronomes sujeitos, como "ele(s)" e "ela(s)", em lugar de pronomes oblíquos. Em contraste com a versão de Lobato, a tradução de Jusmar Gomes aproxima-se mais da coloquialidade, em exemplos como "Podes crer!" e "Vai ver que ele pensou que..." ("vai ver" sendo uma opção mais informal como tradução de "maybe/mabbe"); com o emprego de reduções fonéticas como "tá", "pra" e "pros" (em vez de "está", "para" e "para os"), e o uso de "a gente" (em vez de "nós"). Há uma ocorrência do pronome sujeito "ele" em lugar de oblíquo, o que torna a passagem mais coloquial também: "eu entregava ele pros brancos". A primeira fala do diálogo, porém, sugere um equívoco (do tradutor ou de impressão), já que a oração tende mais à agramaticalidade do que à coloquialidade: “[...] coragem de entregar aquele negros pros brancos?". Apesar da tradução de Jusmar Gomes apontar para uma linguagem mais propensa para a coloquialidade, não há, ao longo de toda a narrativa, qualquer tentativa de se recriarem os elementos linguísticos provenientes da origem socioeconômica marginal dos personagens negros. Estes não falam de modo distinto dos personagens brancos, já que todos produzem falas que, mais ou menos, se aproximam do coloquial, em geral no interior do português padrão. Desse modo, apenas o aspecto diafásico da fala (caracterizado pelo registro informal) é trazido à tona em sua tradução, e não o diastrático (que demarca as diferenças entre classes sociais). A tradução de Aurora Neiva, por outro lado, recria as características que demarcam a origem socioeconômica dos personagens negros, chamando a atenção para o lugar sociodiscursivo que ocupam. Há um envolvimento evidente com a representação da fala não padrão na tradução, como por exemplo, com "craro que tinha", "notiça", "esses branco", "corage", "andaro dano porrada", entre outros recursos linguísticos. Na 
AMORIM, L. M. - O (não) engajamento em traduções da literatura afro-americana no Brasil: o caso de Filho Nativo, de Richard Wright

introdução teórica de sua tese de doutorado, na qual a autora propõe uma terceira tradução do romance de Wright, como anexo de sua tese, Neiva explica que o uso que faz de marcas não padrão da língua portuguesa tem por objetivo dar visibilidade às minorias oprimidas. Suas opções tradutórias têm um caráter estético, mas não menos político e de engajamento social. A tradutora, porém, reconhece que essas marcas de não padrão não são exclusivas de falantes afrobrasileiros, sendo empregadas também por brancos pobres. Segunda a tradutora, a opção por essas marcas não representaria uma fal ha na proposta de sua tradução:

Muito pelo contrário, [essa opção] ajuda a destacar a interpretação à qual prometo fidelidade: a dimensão universal e atemporal da advertência feita por Wright contra os efeitos da opressão social, econômica, racial e cultural vividos pelas minorias afro-americanas dos anos 30. Embora associados principalmente com a classe social e com a formação educacional dos personagens, os aspectos linguísticos pelos quais optei deliberadamente apontam para a questão racial focalizada na narrativa, possibilitando a sua repercussão junto à comunidade interpretativa brasileira como um problema que também concerne à experiência brasileira. Ao conceber Bigger Thomas e todos os demais personagens negros, expressando-se na língua falada pela grande maioria dos afro-brasileiros, o segmento da sociedade brasileira que mais tem sofrido intensamente privações de todo tipo e que, portanto, não domina o dialeto social de prestígio, eu pretendo fornecer os meios pelos quais os leitores de minha tradução possam ouvir a si mesmos, permitindo, assim, que desnudem o preconceito e a discriminação ocultados sob o mito brasileiro da democracia racial. Praticamente incólume desde a época da publicação da primeira tradução de Native Son, o mito brasileiro da democracia racial ainda constitui, em grande medida, uma parte da autoimagem brasileira acerca das relações interétnicas, a despeito da quantidade de pesquisas, realizadas na área da antropologia e da sociologia, que têm desvelado a realidade por trás dessa estimada ideologia. O romance de Wright nos possibilita fazer uso da história de Bigger Thomas como uma advertência que pode ecoar nas mentes de sociedades como a brasileira, que continua a tratar suas minorias, seus próprios "filhos nativos", como párias sociais. O "gueto invisível" (Moura, 1988, p. 13) em que os afro-brasileiros viveram no passado e que 
Amorim, L. M. - O (não) engajamento em traduções da literatura afro-americana no Brasil: o caso de Filho Nativo, de Richard Wright

ainda vivem no presente, é algo que muitos brasileiros não parecem estar dispostos a admitir, acreditando que não há nenhuma discriminação racial em sua sociedade (NeIVA 1995: 88, destaque da autora).

A tradução de Neiva é caracterizada pelo intuito de se questionar o mito da democracia racial predominante no Brasil. Ao dar vozes aos personagens negros por meio de uma linguagem que desnuda seus lugares de marginalidade na sociedade, a tradutora pretendeu chamar a atenção dos leitores brasileiros para a dissonância do texto traduzido, o que poderia conduzi-los à observação da própria realidade desigual no Brasil e dos seus preconceitos (econômicos, "raciais" e linguísticos), em comparação às referências marcadas pelo racismo contra os negros norte-americanos no romance de Wright. Sua proposta de tradução pressupõe uma dimensão de engajamento com uma forma de conscientização acerca de questões étnico-sociais brasileiras que não se faz presente nas traduções anteriores. A tradução de Lobato estava compromissada com uma proposta de “ilustração" do leitor médio nos anos 40, fundamentada na ideologia da Coleção Biblioteca do Espírito Moderno, que pregava a difusão da literatura e dos valores da democracia liberal ocidental (incluindo a norte-americana), de modo que a tradução evitou a propagação dos ideais comunistas do prefácio de Wright, omitindo-o da edição, bem como buscou produzir diálogos numa linguagem padrão que também pudesse ser representativa do ideal do "bom português literário", já que seria supostamente inadmissível, em um país com alto índice de analfabetismo, qualquer tentativa de reprodução de variantes socioletais em um texto traduzido, possivelmente compreendidas apenas como "erros de português" que deveriam ser evitados a todo custo.

A tradução de Jusmar Gomes, por sua vez, embora seja uma versão linguisticamente mais atualizada do romance de Wright, ao fazer o emprego mais ou menos frequente de coloquialismos e de certas marcas de oralidade, indistintamente para brancos e negros, produz um efeito muito menos socialmente 
AMORIM, L. M. - O (não) engajamento em traduções da literatura afro-americana no Brasil: o caso de Filho Nativo, de Richard Wright

dissonante do que aquele produzido na tradução de Neiva Soares, que chama a atenção do leitor para a heterogeneidade linguística e social dos personagens negros em comparação aos brancos. Nesse sentido, é interessante observar que, na tradução de Jusmar Gomes, o emprego regular de certas marcas de oralidade nas falas dos negros, em vez de marcas linguísticas de português não padrão, aproxima muito mais esses personagens dos leitores brasileiros de classe média, prováveis consumidores da referida tradução. Assim, na medida em que os personagens negros não falam um português não padrão, mas apenas um registro de maior informalidade, sua linguagem produz um efeito de familiaridade e "consonância" (em oposição à "dissonância" da tradução de Neiva Soares) junto aos leitores brasileiros de classe média, que podem, talvez, visualizar nos personagens negros norte-americanos, algo em comum, não necessariamente com os negros brasileiros pobres, mas consigo mesmos, pelo menos do ponto de vista do seu habitus linguístico, já que ele seria menos atrelado a formas linguísticas não padrão que são tipicamente estigmatizadas e associadas às classes sociais menos favorecidas e com menor grau de escolaridade. Isso possibilitaria, de certa forma, a construção de uma "empatia" maior (ou, dito de outra forma, uma "antipatia" menos acentuada) do leitor brasileiro em relação à configuração das ações trágicas associadas à figura de Bigger Thomas, bem como às condições linguisticamente contrastantes entre as falas dos demais personagens negros e as dos brancos, no texto em inglês. Em outras palavras, a tradução da editora Best Seller produz um efeito semelhante à afirmação hipotética, por exemplo, de que entre "eles" (os "negros" norte-americanos) e "nós" (leitores brasileiros de classe média) não haveria diferenças tão gritantes assim: afinal, "somos todos humanos", e haveria inclusive uma condição de humanidade no drama das ações criminosas de Bigger Thomas. A linguagem, no caso da tradução, aproxima brancos e negros pela via da coloquialidade, sendo, assim, inscrita na metáfora de uma humanidade ideal que subjaz o mito ou o sonho da democracia racial que permeia o imaginário 
AMORIM, L. M. - O (não) engajamento em traduções da literatura afro-americana no Brasil: o caso de Filho Nativo, de Richard Wright

da cultura brasileira em face das nossas relações interétnicas. A tradução de J usmar Gomes torna, desse modo, a experiência de Bigger Thomas e de seus pares, menos dissonante, mais propícia à possível aceitação de sua trágica e violenta humanidade pelos leitores brasileiros.

A tradução de Aurora Neiva, por ser estética e linguisticamente mais "dissonante", convida o leitor à experiência conflituosa da linguagem mais heterogênea dos personagens negros, apostando não na aceitação ou empatia dos leitores perante aqueles ${ }^{4}$, mas na deflagração das injustiças sociais brasileiras (traduzidas na variação linguística estigmatizada), trazendo à tona, inclusive, 0 risco de ver sua tradução rechaçada por leitores mais conservadores e imbuídos de uma visão informada pelo preconceito linguístico. Sua tradução não foi efetivamente publicada, muito provavelmente porque os direitos de publicação da tradução de Native Son, no Brasil, em 1995, ainda estariam em mãos da Best Seller, editora da tradução de J usmar Gomes. Embora Trmoczko (2010: 12) afirme que "o engaj amento como uma metáfora do ativismo na tradução tem por obj etivo formas de ação mais diretas e mais poderosas do que meras mudanças de atitude [attitudinal shifts]", o que implicaria geralmente o trabalho conjunto de tradutores em torno de um mesmo ideal político para que ele venha a se concretizar, não se deve julgar que a não publicação da tradução de Aurora Neiva a exclua da condição de uma versão engajada com uma perspectiva discursiva voltada para a visibilidade, ainda que indireta, das desigualdades "raciais" e econômicas no Brasil. Não há dúvida de que os efeitos que ela poderia ter, se publicada, seriam imprevisíveis, já que, por exemplo, não há como garantir que

\footnotetext{
${ }^{4}$ Vale ressaltar, por exemplo, que, diferentemente do processo mais "amenizador" das traduções de Monteiro Lobato e de Jusmar Gomes, na tradução de Aurora Neiva enfatiza-se a referência a "rape" (discutida anteriormente) como o "estupro" a que Bigger Thomas considerou ser submetido diariamente, demonstrando que a tradutora não buscou desenvolver uma "empatia" junto aos leitores perante a figura de Bigger Thomas, mas, antes, ensaiou produzir um ef eito de consternação e dissonância que poderia levar o leitor a uma conscientização mais aguda da condição de desigualdade racial e econômica, tanto nos EUA quanto no Brasil.
} 
AMORIM, L. M. - $O$ (não) engajamento em traduções da literatura afro-americana no Brasil: o caso de Filho Nativo, de Richard Wright

certos leitores não se sintam incomodados com as falas dos personagens negros, por julgarem que elas poderiam "estereotipar" suas próprias autoimagens: é o que poderíamos imaginar no caso de possíveis leitores afro-brasileiros de classe média e com nível de educação superior (o que certamente é mais comum hoje em dia do que na década de 90 , embora ainda constituam uma minoria da população negra brasileira).

O sentido de engajamento poderia ser concebido de modo mais amplo e não necessariamente como uma forma de ação necessariamente "mais direta" ou "mais poderosa", tal como implicado na concepção de Trmoczko (2010). Engajarse na tradução seria assumir um posicionamento discursivo, de natureza tão estética quanto política, no sentido de propor certas interpretações que podem levar a um determinado resultado, previsto ou não. Nesse sentido, o significado do engajamento poderia ser compreendido muito mais produtivamente nas origens e nas intenções dos seus fundamentos, "para o bem" ou "para o mal", mesmo que os resultados finais pretendidos não tenham sido alcançados. Isso implica afirmar que a noção de "ação", subjacente à ideia de engaj amento, começa com a própria tradução, em si mesma, um ato performativo (cf. ESTEVEs 2014) que, como no caso da tradução de NEIVA (1995), revela um olhar comprometido com a reflexão em torno das desigualdades que se inscrevem na cultura de recepção da tradução, ainda que motivada pelas circunstâncias sociais e raciais que demarcam o texto original. Se sua tradução jamais for publicada na forma de livro (ainda que a mesma esteja disponível, para venda, em um banco de teses online), sua "silenciosa" assinatura deixa uma marca indelével, para além de qualquer movimento coletivo, na memória engajada dos singelos e pequeninos gestos de tradução. 
AMORIM, L. M. - O (não) engajamento em traduções da literatura afro-americana no Brasil: o caso de Filho Nativo, de Richard Wright

\section{Referências bibliográfica}

Esteves, L. Atos de tradução: éticas, intervenções, mediações. São Paulo: Humanitas, 2014.

FonseCA, S. A. A coleção Biblioteca do Espírito Moderno: um projeto de alimentar espíritos da Companhia Editora Nacional (1938-1977). 2010. 352f. Tese (Doutorado em Educação) - Programa de Educação: História, Política e Sociedade - Pontifícia Universidade Católica de São Paulo, São Paulo.

GentZleR, E.; Tymoczko, M. (Org.) Translation and power. Amherst: University of Massachussetts Press, 2002.

HeRmans, T. (Org.) Manipulation of literature: studies in literary translation. New York: St. Martin's Press, 1985.

LEFEVERE, A. (Org.) Translation/ history/ culture: a source book. London/ New York: Routledge, 1992.

MourA, C. Sociologia do negro brasileiro. São Paulo: Ática, 1988.

NeIva, A. M. S. Native Son in Brazilian Portuguese with a study on dialects and translation: a nonlogocentric approach. 1995. 822f. Tese (Doutorado em Inglês) Department of English - Northern Illinois University, Dekalb, Illinois.

PÉREZ, M. C. (Org.) Apropos of ideology: translation studies on ideology - ideology in translation studies. Manchester: St. J erome, 2003.

The Translator. Translation and minority. Manchester: St. Jerome, v.4, n. 2, 1998. Special edition (Ed. Lawrence Venuti).

TYMoczKo, M. (Org) Translation, resistance and activism. Amherst: University of Massachussetts Press, 2010.

Wright, R. Native son. New York: Harper \& Row Publishers, 1966. - Filho nativo: tragédia de um negro americano. Tradução de Monteiro

Lobato. São Paulo: Editora Companhia Nacional, 1944. Coleção Biblioteca do Espírito Moderno.

. Filho nativo. Tradução de J usmar Gomes. Best Seller, 1987. 